\title{
Liquid-Liquid Extraction of Enzymes by Affinity Aqueous Two-Phase Systems
}

\author{
Yan Xu ${ }^{1}$, Maria Aparecida Souza ${ }^{2}$, Marcela Z. R. Pontes ${ }^{2}$, Michele Vitolo ${ }^{2}$ and Adalberto \\ Pessoa Júnior ${ }^{2 *}$ \\ ${ }^{1}$ Department of Chemical Engineering; Hebei Institute of Technology; Tangshan; Hebei; 063009; P. R. China. \\ ${ }^{2}$ Biochemical and Pharmaceutical Technology Department; FCF/USP; C. P. 66083; 05315-970; São Paulo - SP - \\ Brazil
}

\begin{abstract}
From analytical to commercial scale, aqueous two-phase systems have their application in the purification, characterization and study of biomaterials. In order to improve the selectivity of the systems, the biospecific affinity ligands were introduced. In the affinity partitioning aqueous two-phase system, have many enzymes been purified. This review discusses the partitioning of some enzymes in the affinity aqueous two-phase systems in regard to the different ligands, including reactive dyes, metal ions and other ligands. Some integration of aqueous two-phase system with other techniques for more effective purification of enzymes are also presented.
\end{abstract}

Key words: Affinity partitioning, Aqueous two-phase systems, Reactive dyes, Ligands, Enzymes

\section{INTRODUCTION}

Aqueous two-phase systems (ATPS) are generally composed of a water solution of structurally distinct hydrophilic polymers (e.g., polyethylene glycol, dextran) or of one polymer and certain salts (e.g., ammonia sulfate, potassium phosphate). Above critical concentrations of these components, spontaneous phase separation takes place with each of the two resulting phases enriched with respect to one of the components. Initially described by Berjerinck toward the end of $19^{\text {th }}$ century, such phase systems were rediscovered and first employed in the 1950s by Albertsson for the isolation and separation of plant organelles and cell fragments (Albertsson, 1956). Aqueous two-phase systems containing two polymers have found wide application for the separation of most biological materials and systems containing a single polymer and salts have also proved useful in the separation of macromolecules (Albertsson, 1986).

Success with aqueous two-phase systems depends on the ability to manipulate phase composition so as to obtain appropriate partition coefficients $(\mathrm{K})$ and selectivity for the material of interest. There are several ways to manipulate system composition so as to give phases with appreciably different physical properties and the three below are relatively important. (a) choice of polymers, polymer concentration, polymer molecular weight; (b) choice of salt(s) and salt concentration; and (c) chemical modification of one of the polymers by attaching a ligand for which receptors exist on the material of interest. In the last case the resulting procedure is called affinity partitioning.

Affinity Partitioning (AP) is based on the preferential/biospecific interaction between the

Author for correspondence 
molecule and affinity ligands. The interaction results in a biomolecule-affinity ligand complex which selectively partitions to one of the phases leaving the contaminating substances or proteins in the other phase. Most of the reported investigations regarding affinity partitioning pertain to polymer/polymer type aqueous twophase systems. Very few reports are available on polymer/salt type aqueous two-phase systems mainly due to the interference of high salt concentration with the biospecific interactions (Menge et al., 1983). Beside the common factors that affect the aqueous two-phase systems, affinity partitioning is influenced by the number of ligands per molecule, ligand concentration and its binding characteristics. Despite the differences in the type of ligands, certain features of AP are universal and independent of the type of ligand. These are understood better by the thermodynamic models of Flanagan and Barondes (1975):

$$
K=K_{0}\left(K_{L} D_{B} / D_{T}\right)^{\alpha}
$$

Where $K$ and $K_{0}$ are the partition coefficients of proteins in the presence and absence of the ligand respectively; $K_{L}$ is the partition coefficient of the ligand polymer; $D_{T}$ and $D_{B}$ denote the dissociation constants of the ligand with protein molecule in the top and bottom phase respectively, and $\alpha$ is the number of ligand polymer molecules bound per protein molecule. In addition, Cordes et al. (1987) and Brooks et al. (1985) had also proposed mathematical models for the affinity aqueous two-phase partitioning.

In this review, the partitioning of some enzymes in the affinity aqueous two-phase systems is discussed in respect to the different ligands, including reactive dyes, metal ions and other ligands. We also present some integration of aqueous two-phase system with other different techniques to accomplish more effective purification of enzymes.

\section{REACTIVE DYES AFFINITY PARTITIONING}

An approach to improve selectivity is to introduce group-specific substances like coenzymes as affinity ligands. The low cost of triazine dyes has enabled these compounds to be feasible substitutes for coenzymes (Dean et al., 1986) and the dye affinity ligands had been used successfully for the partition of enzymes in aqueous two-phase systems.

\section{Triazine Dyes Bound to Polymers}

Phosphofructokinase (PFK) from rat erythrocyte haemolysates has a high affinity for Cibacron Blue F3G-A ( $\mathrm{Cb})$ covalently bound to polyethylene glycol (PEG) and thus the enzyme can be extracted into the top phase of polyethylene glycol-dextran aqueous two-phase systems containing PEG bound $\mathrm{Cb}$ (PEG-Cb) (Tejedor et al., 1992). Cheng et al. (1990) investigated the extraction of glucose-6-phosphate dehydrogenase (G6PHD) in a PEG3400-Dextran T500 aqueous two-phase system with the addition of polymers carrying charged groups and affinity ligands. These polymers included DEAE-dextran, dextran sulfate, ligand-dextran, ligand-PEG, ligand-Ficoll and ligand-DEAE-dextran, where the ligands used were the Cibacron Blue F3G-A and Procion Yellow HE-3G. It was found that when polyelectrolytes are forced into a phase with salts, they have a very strong effect on the partitioning of the enzymes, and could further enhance or decrease the partition coefficients of the enzymes when reactive dyes are coupled to them.

In order to study the effect of ligand carrier on biomolecule partitioning, Johansson and Joelsson (1987) used dextran of molecular weight 70,000 as carrier for Procion Yellow HE-3G in PEG-dextran aqueous two-phase system. Dextran has the advantage of containing more reactive group than PEG for ligand binding. Even in the moderate dye:dextran molar ratios $(5 \sim 8)$, the partitioning is strongly salt-dependent. The dye-dextran could be directed to either the top or the bottom phase with partition coefficients from 0,02 to 28 by using salts. The partitioning of dye-binding enzymes (G6PDH, lactate dehydrogenase and 3phosphoglycerate kinase), in turn, was determined by the partitioning of the dye-dextran in the twophase system. Consequently, an enzyme could be extracted into either the top or the bottom phase just by using different salts. The same group also extracted lactate dehydrogenase $(\mathrm{LDH})$ from pig muscle homogenate using Procion Yellow HE-3G bound to PEG in a PEG-dextran aqueous twophase system (Joelsson et al., 1994). After affinity partitioning and back-extraction twice with fresh lower phase, a 21-fold purification with a 79\% yield was obtained. Sloan and Elliott (1996) conducted the rapid purification of heart muscle 
enzymes with affinity aqueous two phase system employing the dye as ligand.

With the aqueous two-phase system, Grimonprez et al. (1996) studied the effects of low temperature $\left(-18^{\circ} \mathrm{C}\right)$ on the stability and partitioning of some glycolytic enzymes. The enzymes were phosphofructokinase, glyceraldehyde-3-phosphate dehydrogenase and alcohol dehydrogenase present in a crude extract of bakers' yeast. The partitioning of pure phosphofructokinase, isolated from bakers' yeast, was also examined. The two-phase systems were composed of water, polyethylene glycol, dextran, and ethylene glycol and buffer. The influence on the partitioning of the presence of ethylene glycol, phenylmethylsulfonyl fluoride and polyethylene glycol-bound Cibacron Blue F3G-A was investigated at $-18,0$ and (in some cases) $20^{\circ} \mathrm{C}$. The presence of ethylene glycol, phase polymers and low temperature stabilized all three enzyme activities. Cibacron Blue, an affinity ligand for phosphofructokinase, increased its partitioning into the upper phase with decreasing temperature. Depending on the conditions, various amounts of the enzymes were recovered at the interface, also in systems not containing ethylene glycol.

Morre et al. (1998) studied the partitioning behavior of a drug (capsaicin)-responsive NADH oxidase (tNOX) released from HeLa cells by low $\mathrm{pH}$ treatment followed by heat and proteinase $\mathrm{K}$. When partitioned in a standard $6.4 \%$ PEG 3350/6.4\% dextran T-500 two-phase system, the bulk of the tNOX activity was in the dextran-rich bottom phase. Affinity partition, where the Cibacron blue was coupled to amino PEG 5000 and added to the first two-phase separation step, resulted in the partitioning of activity to the top PEG phase. A second partition with PEG/salts resulted in the release of the tNOX from the Cibacron blue-amino PEG enriched phase into the salt-enriched bottom phase.

Affinity partitioning was also performed at large scale. Cordes and Kula (1986) purified formate dehydrogenase (FDH) directly from cell homogenates of Candida biodinii with aqueous two-phase affinity partitioning using procion red HE3B coupled to PEG6000 as ligand. To separate FDH from PEG-ligand, potassium phosphate was added to this top phase resulting in PEG/Phosphate system. The FDH partitioned to the lower salt rich phase, while the PEG-ligand remained in the top phase, which was separated and recycled. To remove the trace amounts of the ligand complex from the salt phase containing the product, fresh PEG was added to form again a PEG/salt system. Upon separation of the phase, the top phase was recycled and the bottom phase containing FDH was subjected to ultrafiltration (UF) and lyophylization to provide the final product. Tjerneld et al. (1987) also performed a large-scale affinity partitioning for the purification of $\mathrm{LDH}$ from pig muscle using a PEG/Hydroxypropyl starch system with procion yellow HE-3G as ligand.

\section{Triazine Dyes Unbound to Polymers}

Using unbound reactive triazine dyes as affinity ligands, Bhide et al. (1995) studied the partitioning of alcohol dehydrogenase, glucose-6-phosphate dehydrogenase and hexokinase from pressed bakers' yeast in polyethylene glycol (PEG)/potassium phosphate aqueous two-phase system. The various parameters investigated were ligand type and concentration, $\mathrm{pH}$ of the system, phase composition of the system, and molecular weight of PEG. It was found that the best ligands gave an increase in partition coefficient of 2 to 3 times over that in the absence of the ligand.

Lin et al. (1996; 1998) investigated the affinity partitioning of lactate dehydrogenase in polyethylene glycol/salt and PEG/hydroxypropyl starch (PES) aqueous two-phase systems. It was shown that by using free reactive dyes as affinity ligands, lactate dehydrogenase can be purified with affinity partitioning directly from rabbit muscle homogenization. The free reactive dyes not bound to polyethylene glycol showed a strong tendency toward the top PEG-rich phase in aqueous two-phase systems, and thus enhanced the affinity partitioning effect. Wide-ranged reactive dyes were screened in terms of their partitioning abilities for LDH and Cibacron F-3GA was selected. The effects of various parameters on affinity partitioning behavior of $\mathrm{LDH}$, such as phase composition, impurities in raw material, concentration of dyes, $\mathrm{pH}$ of the systems, and addition of salts, were studied. The optimized affinity extraction process has been carried out for the large-scale purification of LDH from rabbit muscle homogenization. The enzyme was recovered with a yield of $81.3 \%$ and a purification factor of 7.4. Both PEG and dyes were recovered and reused directly without lowering the quality of the product. 


\section{The Binding Properties Studies of Enzymes} Aqueous two-phase affinity partitioning can also be taken as a tool for studying enzymes and enzyme-ligands interactions. Kirchberger et al. (1991) used aqueous two-phase systems consisting of dextran and polyethylene glycol to study the partition behaviour of isoenzymes of lactate dehydrogenase from rabbit tissues in the presence and absence of a series of triazine dyes covalently coupled to PEG. The variations in the primary structures of $\operatorname{LDH} 1\left(\mathrm{H}_{4}\right)$ and $\operatorname{LDH} 5\left(\mathrm{M}_{4}\right)$ are reflected by significantly different partition coefficients. A class of dyes exhibiting defined structural elements was able to distinguish between both of these isoenzymes. This may be based on differences in the binding affinity to the catalytic site of the enzyme. The difference in the relative affinities of LDH1 and LDH5 to Procion Blue H-5R, as estimated by affinity partitioning, were corroborated by chromatographic experiments. Affinity partitioning in aqueous twophase systems can be used to predict and to optimize conditions for the fast and simple chromatographic separation of isoenzymes. The same group (Kirchberger et al., 1992) also investigated the affinity partitioning behaviour of isoenzymes of human alkaline phosphatase in the aqueous two-phase system. In the system without a dye ligand, the partition coefficients of the isoenzymes from human intestine and placenta were identical, whereas the isoenzyme from human liver showed a significantly lower partition coefficient under the same conditions. After addition of dye-polyethylene glycol, two groups of dyes possessing substantial affinities to the isoenzymes were found. One, represented by Procion Yellow HE-3G, interacts specifically with the active center of the isoenzymes. Differences in the affinity of the isoenzymes towards the individual dye ligands are caused only by the carbohydrate content, especially by the terminal sialic acid residues. The other group of dye ligands, represented by Procion Navy MX-RB, binds obviously in a more complex fashion involving other binding sites, which are only present in alkaline phosphatase of human liver. Procion Navy MX-RB was found to function as a suitable affinity ligand for the separation of human liver alkaline phosphatase from the other isoenzymes.

Furthermore, NADH oxidase from Thermus thermophilus HB8 was selected to study the interaction of flavoproteins with structurally defined dye ligands (Kirchberger et al., 1994). The fact that the enzyme binds NADH in addition to FAD favors the enzyme as a model for studying the interaction of enzymes with biomimetic ligands. In addition, the crystal structure of the holoenzyme is known. Applying affinity partitioning in aqueous two-phase systems, difference spectroscopy, affinity chromatography and kinetics, results about the chemistry of binding and the binding site(s) for various triazine dyes were obtained. The binding of the dyes to the enzyme is stabilized by hydrophobic and electrostatic forces.

In polyethylene glycol/potassium phosphate aqueous two-phase systems, Wang et al. (1992) investigated the conformational changes in baker's yeast alcohol dehydrogenase (ADH) caused by the interaction of the affinity ligand Procion Blue MX$\mathrm{R}$, at various $\mathrm{pH}$ values. The affinity partitioning of $\mathrm{ADH}$ was effectively carried out at neutral $\mathrm{pH}$ without any damage to the structural conservation. However, the protein become unstable at alkaline $\mathrm{pH}$ and was further denatured in the presence of Procion Blue MX-R. The oligomeric ADH was completely dissociated to the monomer, and the tertiary structure of the subunits was affected by the interaction of the Blue ligand. Hydrophobic residues such as tryptophan initially buried inside might become accessible to a solvent and made denatured $\mathrm{ADH}$ more hydrophobic than in the native state. This affinity ligand promoted partition of the denatured fraction to the top phase, and of the active fraction to the bottom phase, at alkaline $\mathrm{pH}$. The analysis of partitioning behavior in ATPS could be utilized for sensitive detection of the conformational changes in protein structure.

\section{METAL IONS AFFINITY PARTITIONING}

Metal affinity partitioning exploits the affinity of transition metal ions for electron-rich amino acid residues, such as histidine and cysteine, that are accessible on the surface of proteins. When the metal ion is partially chelated and coupled to a linear polymer, such as PEG, the resulting polymer-bound metal can be used to enhance the partitioning of metal binding proteins into the polymer-rich phase of a PEG-salt or PEG-dextran aqueous two-phase system.

Wuenschell et al. (1990) were one of the first to apply metal ions as affinity ligands in aqueous two-phase systems. An aqueous two-phase system 
of PEG-dextran, including an iminodiacetic acid (IDA) derivative of PEG in order to chelate $\mathrm{Cu}$ (II), was used to study the extraction of heme proteins containing different numbers of exposed histidine residues. The same group (Chung et al., 1994) also studied the partitioning of several phosphorylated and nonphosphorylated proteins in a Fe(III)IDAPEG-Dx two phase system.

In PEG/dextran aqueous two-phase systems containing many dyes bound to polyethylene glycol and PEG derivatives containing $\mathrm{Cu}$ (II) complexes of the Red-Violet 2KT, Red-Brown 2KT and Claret 4CT, Zutautas et al. (1992) studied the affinity partitioning of lactate dehydrogenase from rabbit muscle and yeast glucose-6-phosphate dehydrogenase. It was established that lactate dehydrogenase showed a higher affinity when it interacted with dyes without $\mathrm{Cu}^{2+}$ ions in their structure. The same group (Pesliakas et al., 1994) also studied the affinity partitioning of yeast alcohol dehydrogenase (YADH), lactate dehydrogenase from rabbit muscle (MLDH) and lactate and malate dehydrogenases from pig heart (HLDH and HMDH, respectively) in PEG/dextran aqueous two-phase systems containing metal ions $\left(\mathrm{Cu}^{2+}, \mathrm{Ni}^{2+}, \mathrm{Zn}^{2+}\right.$ and $\left.\mathrm{Cd}^{2+}\right)$ chelated by iminodiacetate-poly(ethylene glycol) (IDA-PEG). Using $\mathrm{Cu}^{2+}$-iminodiacetate-PEG $\left(\mathrm{Cu}^{2+}\right.$-IDA-PEG), Otto et al. (1993) investigated the surface of lactate dehydrogenase isoenzymes from different species for the presence of metal chelate binding sites.

Kwon et al. (1999) used Sepharose 4B as ligand carrier for metal ion affinity partitioning of protein in PEG/dextran aqueous two-phase systems. $\mathrm{Cu}$ (II)-bound Sepharose was mixed with protein solution and an aqueous two-phase system. The affinity sorbent was distributed quantitatively to the upper side or the interface. The binding studies of lysozyme to copper-bound gel in PEG/dextran two-phase systems demonstrated the feasibility of this bioseparation process.

In different aqueous two-phase systems, Sivars et al. (2000) investigated the affinity partitioning behavior of an integral membrane protein, cytochrome $\mathrm{bo}_{3}$ ubiquinol oxidase from Escherichia coli. The systems used were different detergent-polymer aqueous two-phase systems containing a metal-chelating polymer, such as polyethyleneglycol-iminodiacetic acid-Cu(II) as well as dextran-iminodiacetic acid-Cu(II). Many non-ionic detergents, such as alkyl(polyethyleneoxide) $\left(\mathrm{C}_{\mathrm{m}} \mathrm{EO}_{\mathrm{n}}\right)$, Triton, Tween and alkylglucosides, form two-phase systems in mixture with polymers, such as dextran and PEG. In general, membrane proteins partitioned strongly to the detergent micelle phase. They showed that it is possible to selectively partition a poly(histidine)-tagged integral membrane protein into the polymer phase by metal affinity partitioning, with a shift in the partition coefficient from 0.015 to 4.8 (300-fold). Silva et al. (2000) studied the partitioning of a crude soybean peroxidase (Glycine max) in an aqueous two-phase system. A liquid-liquid extraction process using metal ligands was developed in two steps with the aim of purifying the peroxidase.

Lin et al. (2000) optimized preparation of iminodiacetic acid-polyethylene glycol (IDAPEG) for immobilized metal ion affinity partitioning in aqueous two-phase systems. IDAPEG was synthesized from PEG in two steps by the reaction of iminodiacetic acid with a monosubstituted derivative of epichlorohydrinactivated PEG. Furthermore, the affinity partitioning behavior of lactate dehydrogenase in polyethylene glycol/hydroxypropyl starch aqueous two-phase systems was studied to clarify the affinity effect of the $\mathrm{Cu}$ (II)-IDA-PEG.

To further elucidate the mechanism of metal ion affinity aqueous two-phase partitioning of proteins, Suh et al. (1990) had advanced a thermodynamic model (Eq.2). The protein was assumed to have $n$ equivalent surface histidine binding sites characterized by a metal ligand association constant, $K_{L}$, and a hydrogen ion association constant $K_{H}$, then:

$$
\frac{K}{K_{0}}=\left[\frac{1+K_{L}^{\prime}[L]+K_{H}[H]}{1+K_{L}^{\prime \prime} \frac{[L]}{K_{P}}+K_{H}[H]}\right]^{n}
$$

Where $K$ and $K_{0}$ are the partition coefficients of proteins in the presence and absence of the ligand respectively; $[L]$ and $[H]$ are the unbound ligand and hydrogen ion concentration; The single and double primes denote the top and bottom phase, and $K_{p}=[L]^{\prime} /[L]^{\prime \prime}$ is the ligand partition coefficient in the two-phase system. 


\section{THE OTHER LIGANDS AFFINITY PARTITIONING}

Besides the dyes and metal ions, there are still another substances, such as enzyme inhibitors, substrates and cofactors etc., that can be used as ligands for the affinity partitioning of enzymes in aqueous two-phase systems. Some examples are showed in table 1.

In the early 1970s, Takerkart et al. (1974) employed $p$-aminobenzamidine ( $\mathrm{PAB})$, a strong inhibitor of trypsin, as affinity ligand for the purification of trypsin. PEG9000-PAB exhibited a highly specific effect. In order to purify $\Delta_{5 \rightarrow 4}$ 3-oxosteroid isomerase (EC 5.3.3.1) from extract of Pseudomonas Testosteroni, an estradiol derivative covalently coupled to PEG (PEG-E $\mathrm{E}_{\mathrm{II}}$ ) was used as the affinity ligand in PEG6000 (7\% w/w)/dextran T80 (12\% w/w) aqueous two-phase system (Hubert et al., 1976).

Table 1 - Affinity partitioning of enzymes in aqueous two-phase systems

\begin{tabular}{lclll}
\hline \multicolumn{1}{c}{ Ligands } & Ligand carriers & \multicolumn{1}{c}{ Enzymes } & \multicolumn{1}{c}{ Systems } & References \\
\hline $\begin{array}{l}\text { p-aminobenzamidine } \\
\text { lecithin }\end{array}$ & PEG & Trypsin & PEG9000/dextran T500 & Takerkart et al., 1974 \\
trimethylamine & PEG & Colipase & PEG6000/dextran T500 & Erlanson-Albertsson, 1980 \\
pepstatin & PEG & Penicillin acylase & PEG4000/phosphate & Guan et al., 1992 \\
& Dextran & Chymosin & Dextran/hydroxypropyl & Chen et al., 1993 \\
palmitate & & & dextran & \\
& PEG & Bacillus subtilis & PEG/dextran & Han et al., 1997 \\
starch & & Neutral protease & & \\
& & Glucoamylase & PEG3000/phosphate & Gouveia et al., 2000 \\
\hline
\end{tabular}

With the combination of $\mathrm{pH}$ and salt, it was led to a purification factor of about 170 after 5 steps extraction. Erlanson-Albertsson (1980) studied the PEG-lecithin as affinity ligand for the partitioning of colipase in PEG6000/dextran T500 system.

Guan et al. (1992) described a method of enzyme release and aqueous two-phase extraction for the separation of penicillin acylase from Escherichia coli cells. Butyl acetate, $12 \%(\mathrm{v} / \mathrm{v})$, treatment combined with freeze-thawing gave up to $70 \%$ enzyme release. In polyethylene glycol/phosphate aqueous two-phase extraction systems the enzyme purity and yield were rather low. Modified PEG, including PEG-ampicillin, PEG-aniline, PEGphosphate, and PEG-trimethylamine, were synthesized and used in aqueous two-phase systems, PEG-trimethylamine was the most satisfactory. A system containing $12 \%(\mathrm{w} / \mathrm{w})$ PEG4000, 8\% (w/w) of which was PEGtrimethylamine, with $0.7 \mathrm{M}$ potassium phosphate at $\mathrm{pH} 7.2$, resulted in the enzyme selective partition being greatly enhanced by charge directed effects. Garg et al. (1994) used a non-ionic detergent (Triton X-114) as ligand carrier in aqueous twophase extraction of proteins. Triton X-114 was modified with Cibacron Blue and partitioned in a polyethylene glycol-hydroxypropyl starch system. When an excess of detergent was used, a threephase system with a detergent-rich middle phase was formed. The detergent-dye conjugate partitioned to this detergent-rich phase. This detergent-dye conjugate was used as an affinity ligand for lactate dehydrogenase. The enzyme was recovered by harvesting the detergent-richconjugate-containing phase and subjecting it to temperature-induced phase separation, whereby the detergent and conjugate formed a separate phase, leaving the enzyme in the water-rich phase. With pepstatin attached to dextran as the ligand, Chen et al. (1993) studied the affinity partitions of pepsin, chymosin, and Endothia parasitica protease in dextran/hydroxypropyldextran aqueous two-phase systems. Purification of chymosin was carried out in this affinity system with a five-step liquid-liquid extraction. The purification factor was 6.2 with a yield of $83 \%$. The same group (Chen et al., 1995) also employed soybean trypsin inhibitor bound to a $\mathrm{pH}$-sensitive reversibly soluble-insoluble polymer (AS-L) as ligand for affinity precipitation of trypsin. Trypsin was purified 5.4-fold from a crude extract with $61 \%$ yield. 
Lu et al. (1997) used hydrophobically modified dextrans, benzoyl dextran and valeryl dextran, to study the interactions between tryptophan residues and benzoyl or valeryl groups by partitioning of tryptophan, tryptophan-tryptophan, poly(lysine, tryptophan), beta-galactosidase and lysozyme in polymer aqueous two-phase systems. The twophase systems used were PEG/dextran, PEG/benzoyl dextran, PEG/valeryl dextran, dextran/benzoyl dextran and dextran/valeryl dextran. Interaction between tryptophan residues and benzoyl or valeryl groups was observed by partitioning of tryptophan containing compounds to the phase containing hydrophobically modified dextran. At a certain phase composition the interactions were increased with increasing number of tryptophan per molecule, and benzoyl groups showed stronger interactions with tryptophans compared to valeryl groups.

In PEG/potassium phosphate aqueous two-phase systems, Bacillus subtilis neutral protease could be moved to the upper phase when PEG-palmitate was substituted for PEG, and was purified to 10.2fold compared to the crude enzyme (Han et al., 1997). Palmitic acid in PEG-palmitate showed not only high affinity to Bacillus subtilis neutral protease but also an activation effect (factor of 2.5) on the proteolytic activity.

Kuboi et al. (1998) investigated the different ligands for selective recovery of proteins in PEG/dextran aqueous two-phase system. The ligands used were nonionic surfactant (Triton and PEG-palmitate) and PEG-bound dye (Cibacron Blue and Procion Yellow). Both the partition coefficient in aqueous two-phase system and the solubility in a PEG solution of Bovine Serum Albumin (BSA) increased significantly with the addition of these ligands, because the surface net hydrophobicity of BSA was increased by the binding of these hydrophobic ligands. On the other hand, these ligands had no effect on the partition behavior and solubility of Carbonic Anhydrase (CAB) and Ovalbumin (OvA), which have no binding sites to the ligands. Control of the surface properties of protein by these specific bindings of ligands could be utilized to improve the separation efficiency in aqueous two-phase system.

In a temperature-induced aqueous two-phase system formed by Triton X-45, Triton X-100 and sodium acetate at $\mathrm{pH}$ 5.5, Miranda et al. (1998) carried out the extractive purification of peroxidase from Glycine max seed coats. A 99\% yield with a 6-fold purification factor was obtained. When the clear top phase was subjected to concanavalin-A affinity chromatography, the purification factor rose to 41 and the yield dropped to $28 \%$.

Using starch as a free bioligand, Gouveia et al. (2000) described the affinity partitioning of glucoamylase in PEG300/phosphate system. The starch showed one-sided distribution to the bottom phase. Filtered broth from submerged cultivation of Aspergillus awamori, containing glucoamylase and contaminants, was submitted to the extraction in the system with starch. In the system without starch, glucoamylase and contaminants are partitioned in the upper phase. Upon starch addition, the partition coefficient of glucoamylase was decreased nine-fold without altering the partition of contaminants.

\section{THE INTEGRATION OF AFFINITY PARTITIONING WITH OTHER TECHIQUES}

For the separation and purification of enzymes, the specialists' task is to develop safe and simple processes to obtain products with high purity. Integrating aqueous two-phase affinity partitioning with other techniques is an efficient method to achieve this purpose. Kopperschlager (1994) recovered phosphofructokinase (PFK) from baker's yeast homogenate combining the PEG/dextran aqueous two-phase system with other nonspecific techniques. First, the baker's yeast homogenate was fractionally precipitated with PEG, followed by affinity partitioning using Cibacron Blue F3G-A bound to PEG as a ligand. This resulted in a 58-fold purification and $67 \%$ yield of PFK. The enzyme was further purified by a DEAE-cellulose batch treatment of the top phase, followed by gel filtration. A 142-fold purification and a $30 \%$ yield was obtained after the filtration.

Stredansky et al. (1993) studied the integration of polyethylene glycol/dextran aqueous two-phase system with affinity chromatography on crosslinked starch during cultivation for the production of $\alpha$-amylase with $B$. subtilis CCM 2722. The medium was drawn from the bioreactor to the external settler during fermentation. After phase separation in the settler the dextran-rich bottom phase with cells was returned to the bioreactor. The PEG-rich top phase was pumped 
to the column with crosslinked starch and returned to the bioreactor after $\alpha$-amylase adsorption. The total productivity of the method was much higher owing to shortening upstream and downstream processing time. The $95 \%$ yield was obtained after its elution from the column.

Integrating the affinity partitioning in aqueous two-phase system with affinity precipitation technique, Dong et al. (1994) purified the lactate dehydrogenase from porcine muscle extract. An enteric coating polymer, Eudragit S100, which can be made reversibly soluble and insoluble by change in $\mathrm{pH}$ was employed as the ligand carrier. The ligand used was Cibacron blue 3GA. The polymer is nearly totally partitioned to the top phase (>98\%) in PEG-dextran aqueous two-phase system. The enzyme, lactate dehydrogenase, was first spontaneously partitioned to the bottom phase in a $6 \%(\mathrm{w} / \mathrm{w})$ PEG $8000-8 \%(\mathrm{w} / \mathrm{w})$ dextran T250 two phase system. New PEG phase and Eudragitdye were then added to the bottom phase, which helped in extraction of LDH to the top phase. After a washing step with a fresh bottom phase, Eudragit-dye-target protein affinity complex was precipitated out from the top phase by lowering the $\mathrm{pH}$ to 5.1. The enzyme was recovered by treatment of the complex with $0.5 \mathrm{M} \mathrm{NaCl}$. A yield of $54 \%$ and a specific activity of 245 units/mg was achieved.

For the recovery of aspartase from Escherichia coli, Lee et al. (1995) developed a simple and rapid scheme which coupled aqueous two-phase extraction with affinity membrane chromatography. The aspartase was recovered and purified from cell homogenate by three successive polyethylene glycol-phosphate aqueous two-phase extractions with high activity yield. During the extraction steps, cell debris, nucleic acids, and most contaminating proteins were removed. The aspartase was recovered in the phosphate-rich phase. The enzyme was further purified by affinity chromatography in which the regenerated microporous cellulose membrane and L-aspartate were used as support and ligand, respectively. The aspartase solution was forced to flow convectively through the pores in which ligand L-aspartate was immobilized on the surface. The overall purification scheme yielded aspartase with a specific activity of 27.3 units $/ \mathrm{mg}$, a 32-fold increase in purity, and a $72 \%$ recovery yield.

\section{CONCLUSIONS}

Addition of affinity ligands to the aqueous twophase partitioning system can greatly enhance the partitioning of enzymes. The biospecific binding of the enzyme with the ligand preferentially move the enzyme to the desired phase. The commonly used ligands include reactive dyes, metal ions and other substances related to the enzymes, such as inhibitors and cofactors etc. Usually, the biospecific ligands are covalently coupled to one phase-forming polymer, most often to polyethylene glycol, and will accumulate in the target phase. Recently, some free ligands without coupled to phase-forming polymer were used in the affinity partitioning of enzymes in the aqueous two-phase systems, that avoid the preparation of ligand-polymer conjugates. It is believed to be more economical and easy to scale-up.

To achieve more effective separation and purification, the integration of the affinity aqueous two-phase partitioning with other techniques is a better choice. The affinity aqueous two-phase partitioning could be coupled to the bioreaction process, and the other separation techniques, such as precipitation and chromatography, could also be carried out in the aqueous two-phase media. This is an area that needs more exploration.

\section{RESUMO}

Tanto em escala de laboratório como industrial, os sistemas de duas fases aquosas podem ser utilizados para a purificação, caracterização e estudos de biomateriais. Para aumentar a seletividade desse sistema, ligantes de afinidade bioespecíficos podem ser utilizados. No sistema de duas fases aquosas por afinidade, muitas enzimas podem ser purificadas. Neste artigo de revisão, a partição de algumas enzimas por esse tipo de afinidade, utilizando diferentes ligantes como corantes e íons metálicos, são discutidas. Além disso, a integração desse sistema de duas fases aquosas com outras técnicas de purificação estão sendo apresentados, com o objetivo mostrar a melhoria da eficiência do processo. 


\section{ACKNOWLEDGMENT}

The authors are grateful to FAPESP for the financial assistance.

\section{REFERENCES}

Albertsson, P. A. (1956), Chromatography and partition of cells and cell fragments. Nature, 177, 771-774.

Albertsson, P. A. (1986), Partition of Cell Particles and Macromolecules. New York : Wiley.

Bhide, A. A.; Patel, R. M., Joshi, J. B. and Pangarkar, V. G. (1995), Affinity partitioning of enzymes using unbound triazine dyes in PEG/phosphate system. Sep. Sci. Technol., 30, 2989-3000.

Brooks, D. E. and Sharp, K. A. (1985), In: Walter, H.; Brooks, D. E. and Fisher, D. (ed.). Partitioning in aqueous two-phase systems. New York : Academic Press. pp. 11.

Chen, J. P. and Jen, J. T. (1993), Affinity partitioning of acid proteases in aqueous two-phase systemsModeling and protein-purification. J. of Chemical Engineering of Japan, 26, 669-675.

Chen, J. P. and Jang, F. L. (1995), Purification of trypsin by affinity precipitation and combining with aqueous two-phase extraction. Biotechnol. Tech., 9, 461-466.

Cheng, L., Joelsson, M. and Johansson, G. (1990), Combination of polymer-bound charged groups and affinity ligands for extraction of enzymes by partitioning in aqueous two-phase systems. J. Chromatogr., 523, 119-130.

Chung, B. H., Bailey, D. and Arnold, F. H. (1994), Metal affinity partitioning. Method Enzymol., 228, 167-179.

Cordes, A. and Kula, M. R. (1986), Process design for large-scale purification of formate dehydrogenase from Candida biodinii by affinity partition. J. Chromatogr., 376, 375-384.

Cordes, A., Flossdorf, J. and Kula, M. R. (1987), Affinity partitioning-Development of mathematical-model describing behavior of biomolecules in aqueous two-phase systems. Biotechnol. Bioeng., 30, 514-520.

Dean, P. D. G. (1986), Affinity tails and ligands. Spec. Publ. Soc. Gen. Microbiol., 18, 147-160.

Dong, G. Q.; Kaul, R. and Mattiasson, B. (1994), Integration of aqueous two-phase extraction and affinity precipitation for the purification of lactatedehydrogenase. J. Chromatogr. A., 668, 145-152.

Erlanson-Albertsson, C. (1980), The importance of the tyrosine residues in pancreatic colipase for its activity. FEBS Letters, 117, 295-298.

Flanagan, S. D. and Barondes, S. H. (1975), A method for purification of proteins using specific polymer-ligands in aqueous polymer two-phase systems. J. Biol. Chem., 250, 1484-1489.
Garg, N., Galaev, I. Y. and Mattiasson, B. (1994), Use of a temperature-induced phase-forming detergent (triton X-114), as ligand carrier for affinity partitioning in an aqueous three-phase system. Biotechnol. Appl. Biochem., 20, 199-215.

Gouveia, T. and Kilikian, B. V. (2000), Bioaffinity extraction of glucoamylase in aqueous two-phase systems using starch as free bioligand. J. Chromatogr. B., 743, 241-246.

Grimonprez, B. and Johansson, G. (1996), Liquid-liquid partitioning of some enzymes, especially phosphofructokinase, from Saccharomyces cerevisiae at sub-zero temperature. J. Chromatogr. B., 680, 55-63.

Guan, Y.; Wu, X. Y.; Treffry, T. E. and Lilley, T. H. (1992), Studies on the isolation of penicillin acylase from escherichia coli by aqueous two-phase partitioning. Biotechnol. Bioeng., 40, 517-524.

Han, J. H. and Lee, C. H. (1997), Effects of salts and poly(ethylene glycol), palmitate on the partitioning of proteins and Bacillus subtilis neutral protease in aqueous two-phase systems. Colloids and Surfaces B-Biointerfaces, 9, 109-116.

Hubert, P., Dellacherie, E., Neel, J. and Baulieu, E. E. (1976), Affinity partitioning of steroid-binding proteins. The use of polyethylene oxide-bound estradiol for purifying $\Delta_{5 \rightarrow 4}$ 3-oxosteroid isomerase. FEBS Letters, 65, 169-174.

Joelsson, M. and Tjerneld, F. (1994), Purification of lactate-dehydrogenase from pig muscle by affinity partitioning. Method Enzymol., 228, 136-143.

Johansson, G. and Joelsson, M. (1987), Affinity partitioning of enzymes using dextran-bound procion yellow HE-3G. J. Chromatogr., 393, 195-208.

Kirchberger, J.; Kopperschlager, G. and Vijayalakshmi, M. A. (1991), Dye ligand affinity partitioning of lactate-dehydrogenase isoenzymes. J. Chromatogr., 557, 325-334.

Kirchberger, J.; Domar, U.; Kopperschlager, G. and Stigbrand, T. (1992), Interactions of human alkaline-phosphatase isoenzymes with triazine dyes using affinity partitioning, affinity-chromatography and difference spectroscopy. J. Chromatogr. B., 574, 237-245.

Kirchberger, J.; Erdmann, H.; Hecht, H. J. and Kopperschlager, G. (1994), Studies of the interaction of NADH oxidase from Thermus thermophilus HB8 with triazine dyes. J. Chromatogr. A., 668, 153-164.

Kopperschlager, G., (1994), Phosphofructokinase from bakers-yeast. Method Enzymol., 228, 144-153.

Kuboi, R.; Hasegawa, T.; Yamahara, K.; Komasawa, I. and Johansson, G. (1998), Selective recovery of proteins by control of their surface properties utilizing PEG-bound affinity ligands. J. Chemical Engineering of Japan, 31, 618-625.

Kwon, Y. J. and Hatti-Kaul, R. (1999), Protein separation using metal ion-bound particles in aqueous two-phase system. Biotechnol. Tech., 13, 145-148. 
Lee, C. K.; Wang, N. H. and Ju, Y. H. (1995), Purification of aspartase by aqueous two-phase system and affinity membrane chromatography in sequence. Sep. Sci. Technol., 30, 509-519.

Lin, D. Q.; Zhu, Z. Q. and Mei, L. H. (1996), Affinity extraction of lactate dehydrogenase by aqueous twophase systems using free triazine dyes. Biotechnol. Tech., 10, 41-46.

Lin, D. Q.; Zhu, Z. Q. and Mei, L. H. (1998), Process design for purification of muscle lactate dehydrogenase by affinity partitioning using free reactive dyes. Sep. Sci. Technol., 33, 1937-1953.

Lin, D. Q.; Yao, S. J.; Mei, L. H. and Zhu, Z. Q. (2000), Preparation of iminodiacetic acid-polyethylene glycol for immobilized metal ion affinity partitioning. Chinese J. Chem. Eng., 8, 310-314.

$\mathrm{Lu}$, M. and Tjerneld, F. (1997), Interaction between tryptophan residues and hydrophobically modified dextran-Effect on partitioning of peptides and proteins in aqueous two-phase systems. $J$. Chromatogr. A., 766, 99-108.

Menge, U.; Morr, M.; Mayr, U. and Kula, M. R. (1983), Purification of human fibroblast interferon by extraction in aqueous two-phase systems. J. Appl. Biochem., 5, 75-90.

Miranda, M. V.; Fernandez-Lahore, H. M.; Dobrecky, J. and Cascone, O. (1998), The extractive purification of peroxidase from plant raw materials in aqueous twophase systems. Acta Biotechnologica, 18, 179-188.

Morre, D. M.; Sweeting, M. and Morre, D. J. (1998), Aqueous two-phase partition and detergent precipitation of a drug-responsive NADH oxidase from the HeLa cell surface. J. Chromatogr. B., 711, 173-184.

Otto, A. and Birkenmeier, G. (1993), Recognition and separation of isoenzymes by metal-chelatesImmobilized metal-ion affinity partitioning of lactate-dehydrogenase isoenzymes. J. Chromatogr., 644, 25-33.

Pesliakas, H.; Zutautas, V. and Baskeviciute, B. (1994), Immobilized metal-ion affinity partitioning of $\mathrm{NAD}^{+}$-dependent dehydrogenases in polyethylene glycol -dextran two-phase systems. J. Chromatogr. A., 678, 25-34.

Silva, M. E. and Franco, T. T. (2000), Purification of soybean peroxidase (Glycine max), by metal affinity partitioning in aqueous two-phase systems. $J$. Chromatogr. B., 743, 287-294.

Sivars, U.; Abramson, J.; Iwata, S. and Tjerneld, F. (2000), Affinity partitioning of a poly(histidine)tagged integral membrane protein, cytochrome $b_{3}$ ubiquinol oxidase, in a detergent-polymer aqueous two-phase system containing metal-chelating polymer. J. Chromatogr. B., 743, 307-316.

Sloan, R. and Elliott, R. J. (1996), Rapid purification of heart muscle enzymes using dye affinity aqueous two-phase systems. Biochemical Society Transactions, 24, S119-S119.
Stredansky, M.; Kremnicky, L.; Sturdik, E. and Feckova, A. (1993), Simultaneous production and purification of bacillus-subtilis $\alpha$-amylase. Appl. Biochem. Biotechnol., 38, 269-276.

Suh, S. S. and Arnold, F. H. (1990), A mathematical model for metal affinity protein partitioning. Biotechnol. Bioeng., 35, 682-690.

Takerkart, G.; Segard, E. and Monsigny, M. (1974), Partition of trypsin in two-phase systems containing a diamidino- $\alpha, \omega$-diphenylcarbamyl poly(ethylene glycol), as competitive inhibitor of trypsin. FEBS Letters, 42, 218-220.

Tejedor, M. C.; Delgado, C.; Grupeli, M. and Luque, J. (1992), Affinity partitioning of erythrocytic phosphofructokinase in aqueous two-phase systems containing poly(ethylene glycol)-bound cibacron blue - Influence of $\mathrm{pH}$, ionic-strength and substrates effectors. J. Chromatogr., 589, 127-134.

Tjerneld, F.; Johansson, G. and Joelsson, M. (1987), Affinity liquid-liquid extraction of lactate dehydrogenase on a large-scale. Biotechnol. Bioeng., 30, 809-816.

Wang, W. H.; Kuboi, R. and Komasawa, I. (1992), Stability and partition of alcohol-dehydrogenase in polyethylene glycol - phosphate affinity aqueous two-phase systems using triazine dye. J. of Chemical Engineering of Japan, 25, 134-139.

Wuenschell, G. E.; Naranjo, E. and Arnold, F. H. (1990), Aqueous two-phase metal affinity extraction of heme-proteins. Bioprocess Eng., 5, 199-202.

Zutautas, V.; Baskeviciute, B. and Pesliakas, H. (1992), Affinity partitioning of enzymes in aqueous two-phase systems containing dyes and their copper (II), complexes bound to polyethylene glycol. J. Chromatogr., 606, 55-64.

Received: November 09, 2001; Revised: June 27, 2002; Accepted: March 14, 2003. 